\title{
Minando la traducción: marginalidad, memoria y traducción del extremo cultural
}

\author{
Mining the translation: marginality, memory, \\ and translation of the cultural extreme \\ A minar a tradução: marginalidade, memória \\ e tradução do extremo cultural
}

\section{Catherine Boyle}

\author{
KING'S COLLEGE LONDON, INGLATERRA
}

Profesora en el Department of Spanish, Portuguese, and Latin American Studies en King's College London. PhD, University of Liverpool. Su trabajo intersecta los estudios sobre teatro, performance y traducción en Latinoamérica. Como traductora teatral ha permitido la circulación de la dramaturgia escrita en español en los escenarios del Reino Unido. En 2017, estrenó Mad Man, Sad Woman, traducción de El loco y la triste, de Juan Radrigán. Es cofundadora del fournal of Latin American Studies, autora de Chilean Theater, 1973-1985: Marginality, Power and Selfhood (Fairleigh Dickinson UP, 1992) y coeditora, con David Johnstone, de The Spanish Golden Age in English: Perspectives on Performance (Oberon, 2007). Además, es investigadora principal de los proyectos Out of the Wings: Spanish \& Spanish American Theatres in Translation y Language Acts and World Making (2016). Correo electrónico: catherine.boyle@kcl.ac.uk

\footnotetext{
Artículo de reflexión.

Traducción del inglés al español de Raquel Rivas Rojas.

Documento accesible en línea desde la siguiente dirección: http://revistas.javeriana.edu.co doi:10.11144/Javeriana.cl21-42. $\mathrm{mtmm}$
} 


\section{Resumen}

La escena del rescate de los mineros chilenos (2010)

- entretenimiento multimediático y globalinvita a plantear una serie de preguntas por las intersecciones entre traducción, subjetividad, agenciamientos y mediaciones culturales. Consecuentemente, este artículo explora - a través de un proceso de traducción de textos dramáticos hispanoamericanos en el contexto inglés - la posibilidad de trasladar, a través de distintos territorios, descripciones culturales densas y significativas para creadores, críticos y audiencias.

Palabras clave: traducción; mediación-cultural; globalización

\section{Abstract}

The scene of the rescue of the Chilean miners (2010) -multimedia and global entertainment- invites us to pose a series of questions about the intersections between translation, subjectivity, agency, and cultural mediations.

Consequently, this article explores, by means of a translation process of Hispanic American dramatic texts in the English context, the possibility of transferring, through different territories, dense and significant cultural descriptions for creators, critics, and audiences.

Keywords: translation; mediationcultural; globalization

\section{Resumo}

A cena do resgate dos mineiros chilenos (2010) - entretenimento multimediático e global- convida-nos a colocar uma série de perguntas pelas interseções entre tradução, subjetividade, agenciamentos e mediações culturais. Consequentemente, este artigo explora —através de um processo de tradução de textos dramáticos hispanoamericanos no contexto inglêsa possibilidade de transferir, através de diferentes territórios, descrições culturais densas e significativas para criadores, críticos e audiências.

Palavras-chave: tradução; mediação-cultural; globalização

RECIBIDO: 15 DE JULIO DE 2016. ACEPTADO: 08 DE DICIEMBRE DE 2016. DISPONIBLE EN LÍNEA: 29 DE DICIEMBRE DE 2017

\section{Cómo citar este artículo:}

Boyle, Catherine. "Minando la traducción: marginalidad, memoria y traducción del extremo cultural". Cuadernos de Literatura 21.42 (2017): 199-218. https://doi.org/10.11144/Javeriana.cl21-42.mtmm 


\section{"Estamos bien en el refugio los 33": la emergencia de lo traducible}

La traducción de obras de teatro consiste en una serie de actos hermenéuticos que involucran a un número cada vez más creciente de participantes que cumplen una función específica en el proceso que conduce a la puesta en escena final. En este sentido, se trata de un proceso al mismo tiempo singular y múltiple. El texto es sometido a una serie de interrogaciones, distintas en cada etapa del proceso, y es esta multiplicidad la que crea las condiciones a través de las cuales el proceso colectivo de la producción teatral conduce a la puesta en escena. Es por eso que resulta crucial que los límites entre los distintos papeles posibiliten al mismo tiempo el intercambio creativo y la distancia y el respeto necesarios, así como el uso apropiado de las habilidades que permitan que se desarrolle la serie de actos hermenéuticos requeridos para llegar a la puesta en escena. Esta negociación es parte integral de cada traducción para el teatro, se trate de Shakespeare en un extremo o de nuevos autores en el otro. Los clásicos han acumulado tanto capital cultural que no hace falta explicar el deseo de traducirlos o de "revivir" las obras. Tanto en su versión original como en las traducciones, aceptamos que la interrogación a la que debemos someter al texto es al mismo tiempo compleja y necesaria. Con respecto a la traducción de obras de teatro más recientes, esta interrogación es también fundamental; incluso cuando el impulso de traducir surge de un solo aspecto de su fuerza inicial - por su mensaje social o político, por su dramaturgia innovadora, por ejemplo- el proceso debe ponerse en marcha con el fin de crear continuidad y fluidez en el acto de llevar la obra de una a otra cultura.

La exploración de la idea de traducir los límites culturales surge, en este contexto, del reto de traducir obras de teatro que han sido escritas, en primera instancia, con el fin explícito de parecer extrañas en su propio ambiente. Este es un teatro que emerge de los extremos y representa las experiencias límites vividas, compartidas y recordadas por la comunidad de la cual han surgido los involucrados en la experiencia misma de la representación. La traducción de estas obras a un nuevo ambiente puede resultar dos y hasta tres veces más extraña. Pero lo que tiene más relevancia en este caso es que, desde el punto de vista de la cultura receptora, la aproximación a estas obras constituye una experiencia extrema en términos históricos, geográficos y vivenciales. Esto significa que, en la superficie, parecen no tener nada que comunicarnos, porque nuestra realidad es muy diferente, o porque no nos permiten la comodidad de la diferencia extrema, que nos impide reconocer los vínculos con los relatos y las realidades de esa otra cultura. Para usar 
un ejemplo extremo, resulta mucho más aceptable en varios sentidos aceptar obras que se refieren a torturas o a abusos de los derechos humanos en América Latina, porque se trata de historias lejanas que pensamos que ya conocemos y que nos ofrecen el consuelo de creer que tienen poco que ver con nuestra realidad, que presentar obras de teatro actuales que, más allá de que provienen de un extremo cultural, en realidad nos hablan de nuestra propia experiencia de vida. Y eso implica poner un espejo delante de lo que tenemos en común y lo que pertenece a nuestra propia cultura, que es algo que podemos ver a través de la opacidad de la diferencia. La complejidad proviene, por supuesto, del hecho de que la obra pertenece a "sistemas interconectados" (Schechner X) constituidos por los múltiples elementos que determinan la producción misma y que nos empujan más allá de las abstracciones académicas. Una preocupación clave en el análisis crítico y creativo de las obras que provienen de lo que consideramos como un extremo cultural es preguntarse cómo la puesta en escena puede trastornar el papel "visceral" del público, para usar la terminología de Schechner, que espera "una satisfacción de parte de los actores que están a cargo de suministrar con sus actuaciones la puesta en escena" (Schechner 18).

Cuando hacemos traducciones desde culturas extremas aprendemos de ese proceso hermenéutico y lo que se nos revela a partir de la exploración de ese extremo cultural es lo que queda (radicalmente) en pie una vez que el exceso de diferencia ha sido desplazado. Es esto lo que da lugar al reconocimiento. Esta no es una consideración académica sino una profunda preocupación cultural, que tiene que ver con el hecho de que la traducción, la mediación cultural, debe ocupar el espacio y proporcionar la oportunidad de contribuir con la reflexión, el agenciamiento, el cambio, la renovación y lo radical. Con el fin de pensar en esta idea de una forma más creativa y sugerente debemos tomar distancia de cualquier punto fijo ubicado en el centro imaginario del proceso y mantenernos siempre en movimiento entre lugares de articulación y escenificación, de manera que podamos desplazarnos con el texto y dentro de él, comprendiéndolo desde el punto de vista de sus espacios de producción. El objetivo es fomentar una práctica comprometida con la comunidad de voces en traducción dentro de cualquier obra, y la preocupación principal aquí es cómo descargar al texto distante de la trampa del extremo cultural y desarrollarlo para su puesta en escena.

Si aceptamos junto con Lawrence Venuti que "las traducciones sólo hacen posible una comprensión domesticada" (483), el problema que configura nuestra aproximación es cómo usar las ganancias y las pérdidas implícitas en 
esta apropiación y "personificación", en términos de Steiner (319), de la obra traducida en relación con la cultura receptora. ¿Cómo activamos el proceso de transformación con el fin de cuestionar la cómoda creación de un tipo de espacio transparente a través del cual la percepción del otro distante parezca clara y nítidamente separada de la experiencia del público y, en su lugar, crear un lugar más opaco, cargado de una densidad cultural local? ¿Cómo dar lugar al proceso de producción de las condiciones para una densidad de la representación que sea sostenida, múltiple y modulada? Mi respuesta es trabajar de manera instintiva y metodológica con la idea de una "descripción densa" (Geertz 14), que es el espacio perfecto de la traducción, así como el concepto de "traducción densa", que toma en cuenta el impacto que tiene nuestra percepción problemática de la diferencia (Appiah 342).

En este contexto, la posición del traductor consiste en adoptar la subjetividad en los objetivos específicos de entrar y salir del contexto cultural de la obra original que busca vincularse con lo que Steiner llama "la negación de la entropía", a través de la cual las estructuras simbólicas densas son "conservadas a ambos extremos del ciclo, tanto en la fuente como en el receptor" (318). No se trata de producir equivalencias, un "doble "perfecto" (318). De lo que se trata es de recrear los medios a través de los cuales la obra logre, por un lado, tener una existencia "densa" en la nueva cultura, así como tener sentido a partir de una nueva fractura del reconocimiento y el significado, y, por otro, llamar la atención sobre los nuevos sentidos que pueda generar. Aquí, la posición subjetiva se refiere a que hay obras que dan pie a una forma de domesticación radical que permite borrar la ilusión de la diferencia que convierte en invisible la posible intervención ideológica de la obra en la cultura receptora. Estos son los textos que están en el centro del proyecto de traducir los extremos culturales.

Quiero explorar aquí el tema de la traducibilidad potencial en términos de transferencia cultural, de la opacidad cultural y política y el tipo de decisiones que deben tomarse para cada obra específica cuando alguien en el equipo traductor está a cargo de representar el rol de mediador cultural, que es, por supuesto, uno de los más profundos y relevantes en términos históricos para la obra traducida. Lo que me intriga es el tipo de agenciamiento que se genera en la forma en que las historias son transmitidas, en cómo se eligen los hilos específicos de un relato, cómo se siguen y se reproducen de acuerdo a su nivel de reconocimiento y a cómo pueden convertirse en formas de advertencia, para hacer que la cultura receptora esté atenta a lo que está sucediendo. De este modo, la diferencia en el escenario que estoy señalando 
aquí es la que permite una transformación a través de la domesticación radical y, por tanto, de la borradura de la misma diferencia. ¿Cómo elegimos las historias que queremos volver a contar y a reformular para convertirlas en relatos propios? Comenzaré con el ejemplo de un espectáculo transmitido globalmente que nos permite preguntarnos por lo que está debajo de la superficie de una traducibilidad aparentemente transparente.

El 13 de octubre de 2010, millones de personas en todo el mundo siguieron a través de los medios el rescate espectacular de 33 mineros que habían quedado atrapados en la mina San José, en el desierto de Atacama en Chile. Uno de los mineros recuerda que ellos sabían desde muy temprano que se estaban haciendo intentos de rescatarlos y que sabían por dónde estaban taladrando, porque "los ruidos se transmiten a través de las rocas". Habían quemado neumáticos para enviar señales de humo que mostraran su ubicación exacta, pero en ese momento los rescatistas, que estaban a 700 metros en la superficie, no supieron cómo leer el humo y no lo interpretaron como un mensaje de los mineros. Finalmente, diecisiete días después de haber quedado atrapados, fueron capaces de enviar a la superficie, en la sonda que los había localizado, una serie de mensajes, entre los cuales estaba el ya icónico "estamos bien en el refugio los 33". A medida que el largo proceso de rescate fue desarrollándose de manera impresionante, aunque dolorosamente lenta, la prensa informaba que los 33 mineros habían acordado un pacto de silencio para que ninguno hablara de forma individual de las "cosas terribles" que habían pasado en la mina en los 17 días que transcurrieron antes de que los localizaran. Cuando salieron a la superficie estaban todos limpios y recién afeitados. El líder de los rescatistas recuerda que uno de los mineros le dijo: "Me quería dejar la barba, pero me di cuenta de que no debía hacerlo, porque mi familia se iba a preocupar". "Si se hubiera dejado la barba [dijo el rescatista] lo hubieran visto como un hombre destruido, derrotado, y eso no hubiera sido bueno. Por eso dijeron que iban a salir bien afeitados y bañados". ${ }^{1}$

Esta decisión muestra el impulso de crear un relato dominante y compartido de la misma experiencia que permitiera organizarlo en una narrativa que tuviera sentido para aquellos que no la habían vivido. Pero, fundamentalmente, esto les permitía controlar la historia dentro de ciertos límites de lo que se puede contar tanto sobre la naturaleza de esa experiencia como sobre las realidades más generales del oficio histórico de la minería. En el

1 Las citas provienen de distintas notas de prensa. Hay un excelente recuento de los hechos realizado por el periodista Jonathan Franklin, 2011. 
relato que decidieron compartir públicamente, los mineros buscaban crear puntos de reconocimiento al contar fragmentos de su historia que pudieran encontrar un eco que resonara en las experiencias compartidas y los miedos imaginados de toda la comunidad. El lenguaje que utilizaron solo podía venir de su propia comunidad cultural y a partir de ese lenguaje accesible se produjo una sensación de reconocimiento y simpatía. Ahí radicó el poder tanto de la nota original - que fue el primero de los muchos mensajes enviados luego a través de la sonda- y de la declaración del minero Mario Sepúlveda, conocido como "el animador": "Estuve con Dios, estuve con el Diablo y me pelearon y me ganó Dios. Me agarré de la mejor mano". El ritmo y la estructura de sus frases, igual que la nota que anunció su supervivencia, tienen una resonancia aurática inmediata, una profunda memoria rítmica, intuitiva y corporal, y un sonido que produce la sensación de que la historia pertenece a relatos que ya se conocen, que ha surgido de esos relatos conocidos.

Sin embargo, ¿qué hizo que el rescate de los mineros se convirtiera en un evento disponible de una manera tan devastadora y directa, como para ser contado en todo el mundo? La excelente misión de rescate nos llamó por supuesto la atención por su ingenio, tenacidad y eficiencia. La posibilidad de que en un país como Chile, que está en el fin del mundo y que apenas se sostiene en una franja de tierra- como demostró el terremoto de marzo del mismo año-, se pudieran movilizar equipos con semejantes habilidades técnicas resultó de entrada una sorpresa para la sensibilidad del público del "primer mundo". Una maquinaria publicitaria, perfectamente administrada, capitalizó esta noticia, colocando a Chile al frente de la innovación tecnológica, el cuidado psicológico de los mineros y la gerencia del inmenso Campamento Esperanza, en el que las familias de los mineros se establecieron a la vista de los medios de comunicación por todo el tiempo que duró la operación de rescate, con un orgullo tenaz y una clara conciencia de que se trataba de un momento de cambio fundamental en relación con el prestigio internacional del país. Pero me parece que la clave es en realidad esta: el espectáculo ofrecido por 33 momentos de olvido perfecto. Treinta y tres veces se nos ofreció la oportunidad de observar el momento exacto en el que la perfección era posible. Y los mineros contribuyeron silenciando sus historias personales, con sus caras recién afeitadas y sus cuerpos lavados, incluso al utilizar lentes de sol de una marca muy conocida (Franklin). Y, sin embargo, el olvido perfecto que se reactivaba en cada uno de esos renacimientos recurrentes, que muy pronto se asemejaron a un ritual, se fracturó inmediatamente. Su fugacidad se hizo evidente de manera inexorable en el contexto cultural del que surgió y de allí salieron también los 
elementos a partir de los cuales iba a ser evaluada esa experiencia. Entre los repetidos momentos del rescate, la imagen heroica de los mineros ya había sido puesta en entredicho por los medios, en las complicadas biografías que se dieron a conocer de algunos de ellos y en las evocativas historias personales que presentaban flaquezas humanas fácilmente reconocibles. Los momentos de perfección transmitidos alrededor del mundo habían sido afectados por mucho más que el impulso sensacionalista de la prensa que buscaba historias normalizadoras de interés humano, o por la serie de titulares melodramáticos que llenaron las horas de espera entre uno y otro renacimiento proveniente de las entrañas del suelo chileno.

Las preguntas que surgen del rescate de los mineros no se refieren, como sugirieron los medios británicos de manera superficial, a la posibilidad de que Pinochet fuese eclipsado por este evento como el principal referente en relación a Chile (que a su vez es un asunto que evoca el olvido, por ejemplo, de la admiración que sentía Margaret Thatcher por el dictador, o las medidas económicas neoliberales que utilizaron actitudes similares hacia los sindicatos y las organizaciones de trabajadores, o el arresto domiciliario de Pinochet en Surrey, en 1998). Se trata de un asunto de traducibilidad. Este rescate, seguido a lo largo de 69 días de dramatización televisiva de lo que podía hacerse comprensible de la experiencia de los mineros que emergían de las rocas, proporcionó un adecuado final, perfecto e inteligible a nivel internacional, a una historia que con demasiada frecuencia se repite con un final trágico. ${ }^{2}$ Desde afuera, nuestro contacto inmediato con la experiencia es a través del argumento, que una vez que se desarrolla, se vincula a una poderosa estructura narrativa de pérdida y redención. Esto es lo que queda en pie luego de la traducción a otras muy diversas culturas, a menos que conexiones más complejas produzcan otros reconocimientos más profundos y, tal vez, una conciencia más amplia de la densidad de los muchos niveles de reconocimiento y distancia que le proporcionan a este evento una significación en la cultura receptora; un reconocimiento que lo "domestique" lo suficiente para que se convierta en algo más que un espectáculo. Comprender el espectáculo global del rescate de los mineros, como una forma de traducción gestionada minuciosamente en su proyección y recepción, es entrar en todos los niveles de decisiones tomadas sobre qué aspectos deben darse a conocer y qué se puede compartir. Lo que se refleja en las diversas decisiones acerca de lo

2 Mineros en Gales, China y Nueva Zelandia murieron en incidentes parecidos en esa misma época. El mismo día del rescate, murió un joven en una mina de oro cerca de Valparaíso. 
que se reconoce como propio y lo que se mantiene como diferente. En este proceso había muy poco interés en dar a conocer estructuras simbólicas, históricas y políticas que, en su densidad cultural, pudieran dar cuenta de las razones por las que en principio sucedió este accidente. Esto hizo que pasara de ser "una ocurrencia, algo que pasa" a un "componente narrativo" de una historia más amplia (Ricoeur 4). Es como componente narrativo - con toda la densidad cultural que el término sugiere - que el argumento, la historia, se convierte en "traducible" y en susceptible de tener un significado tanto en su propio ámbito como en otros. La línea argumental — su superficie- puede entonces ser reconocida como un conector entre ideologías compartidas, por más inaceptables que parezcan. Porque, más allá de la naturaleza aparentemente simplista del inmediato análisis periodístico, referente a la disminución potencial de la memoria de Pinochet (un análisis nacido, por supuesto, de la inmediatez y las demandas de la cobertura televisiva), queda en pie un asunto que "excede la comunicación del significado universal" (Lecercle citado en Venuti 484), y al volverse múltiple y multidimensional, produce la posibilidad de una compleja conexión cultural, política, social e histórica. El derrumbe, el confinamiento, el rescate, la naturaleza de la mina, la realidad que rodeaba el rescate, todos estos elementos sirvieron para producir memoria y vínculos históricos, políticos y culturales. Detrás de esos 33 momentos de olvido perfecto hay una "marea de memorias" potencial y real, para usar la frase del historiador chileno Gabriel Salazar (253). La pregunta aquí se refiere a cómo estas memorias derivan hacia estas y otras orillas. ¿Qué es lo que no se traduce o lo que no hay ninguna necesidad o deseo de traducir? En el terreno de lo subjetivo, ¿qué aportaría una traducción más profunda y densa de estas historias y cómo ese tipo de traducción podría interrumpir las narrativas dominantes? Estas no son preguntas que se puedan responder aquí, pero son la base de las interrogantes que necesitamos hacernos una y otra vez.

Lo que saca a la superficie la compleja historia del rescate de los mineros es un sentido de la profunda red estructural de significados en la cual opera este relato. Lo que no logró la versión televisada de la historia - porque no era su intención - fue movilizar la densa realidad histórica que estaba en el origen de la catástrofe. La traducción de este elemento - el impulso político de mostrarlo- es lo que posibilita las estructuras de reconocimiento y por tanto de reflexión sobre la propia realidad. Esta idea está impulsada por un pensamiento muy simple: la traducción del rescate de los mineros, como un entretenimiento multimediático global, me hizo pensar de manera apremiante en la subjetividad y los riesgos de la traducción a través del agenciamiento 
y la mediación cultural. En la superficie, no hay razón para pensar que el rescate no sea más que un evento global que reafirma una visión optimista de la vida, manejado a favor de los intereses de Chile. Y, sin embargo, la reflexión sobre esa historia que sucedió allá y lo que está sucediendo aquí, en el lugar de recepción, provoca en mí el deseo, la necesidad, de llamar la atención sobre las similitudes que veo en relación a mi propia comunidad. Esto corre el riesgo de sonar como una abstracción académica, pero proviene en realidad de la convicción de ser capaz de ver las dos orillas: entonces y ahora, aquí y allá. Más que eso, se trata de utilizar el impulso que ofrece el "cuerpo del saber" (Schechner 18) académico para producir una experiencia que está "viva": "estar vivo es cambiar, desarrollarse, transformarse; tener necesidades y deseos; incluso, potencialmente, adquirir, expresar y usar la conciencia"(X).

\section{La traducción densa y la cultura de los vínculos}

La traducción es un movimiento de traslado de un contexto a otro que se realiza a través de una negociación permanente que termina, por razones específicas, en un punto concreto. Se trata de un proceso que lleva dentro de sí la necesidad de un punto final, una interrupción que es necesariamente arbitraria. Un proceso que plantea la pregunta por lo que sabemos ver y por qué tan grande es el deseo de trasladar hacia nosotros ese saber. La traducción para el teatro comparte las mismas condiciones de producción y los objetivos de la creación teatral, que la dramaturga chilena Isidora Aguirre (1919-2011) define como la habilidad de usar el escenario con el fin de crear las condiciones para que la gente sea capaz de ver lo que en otras circunstancias no vería. Aguirre escribió obras de teatro arraigadas de manera elemental en la historia de su tierra y en las luchas de su pueblo. Escribió desde una posición abiertamente política y casi siempre por encargo de la misma gente sobre la cual escribía. Se trata de historias sobre las fallidas y constantes luchas por la tierra, de personas que se sostienen al borde de la miseria escarbando en los basureros, de comunidades destruidas por la violencia política y la represión, de comunidades mineras devastadas. Aguirre es el ejemplo perfecto de una autora de teatro cuyo trabajo, desde una perspectiva británica contemporánea, podría ser considerado transportable pero no traducible. Un objeto para el voyeurismo del dramaturgo politizado y aparentemente unidimensional, en lugar de una autora que se considere válido recuperar íntegra en nuestro contexto. Y, sin embargo, ofrece el ejemplo perfecto de una escritura que comienza a tener sentido hoy en nuestra cultura. Pero para que esto se desplace 
a la traducción y la producción, primero debe producirse el acto de "verlo" desde dentro de la cultura receptora (nuestra cultura, de aquí y ahora, en este momento). Aquí la dificultad está relacionada con el alcance inmediato, porque de entrada ya hay una pérdida en el acto de aproximarnos a otras realidades, que comienza con una ceguera con respecto a nuestra propia realidad, que nos impide ver lo que nos habla de manera latente en esa obra aparentemente distante.

Aquí, la "pérdida" que se produce en el proceso de traducción se refiere a la disminución de la "densidad" del arraigo cultural del texto original y a la ansiedad de encontrar una densidad similar al reubicar el texto traducido. La fuerza de la traducción para el teatro depende de la sostenibilidad de la multiplicidad que crea las condiciones para una nueva densidad cultural. Tanto el original como la traducción necesitan una forma sostenida y compleja de lectura y comprensión. Y es esto lo que no se comparte habitualmente a través de la serie de intervenciones que se dan a lo largo del proceso de traducción. De manera que, aunque la traducción está siempre anclada de forma permanente e inevitable a las fluctuaciones de lo subjetivo, es precisamente esto lo que la vincula a las estructuras simbólicas, culturales, históricas y políticas de conciencia, memoria y saber. $\mathrm{Y}$ es también lo que las une a las estructuras económicas, a la economía de la producción teatral. Esta perspectiva - basada en la posibilidad de agenciamiento del traductor como un profesional de la cultura, que forma parte de un equipo de profesionales del teatro, que está situado en un punto de distancia simbólica entre culturas y que es capaz de verlas al mismo tiempo- ubica mi reflexión y mi práctica como traductora del lado de un decidido reconocimiento de que la "traducción es siempre ideológica" (Venuti 498). Es por eso que la dramatización del rescate de los mineros en Chile dio lugar a mi propia "marea de memorias". Memorias que parecen prestadas, pero que se basan en un saber literario, histórico y político y en una capacidad adquirida de leer signos "para ingresar al mundo conceptual en el que viven los sujetos [...] y dialogar con ellos", como sostiene Clifford Geertz (24). No se trata de considerar la traducción como etnografía sino de movilizar un saber creativamente estructurado y de activar la habilidad de ponerlo en circulación en los distintos giros de la traducción, con el fin de transmitir ese saber y hacerlo llegar a los que van a cumplir otros objetivos a lo largo del proceso. Si, para el etnógrafo, el acceso al otro está en el centro del modo como se maneja la información y la comprensión de otras culturas, para el traductor este acceso se convierte en un primer paso que se repite una y otra vez en la transformación de ese encuentro original con el texto en un conjunto potencial de 
nuevos encuentros posteriores, en una nueva conversación. Una conversación que toma "el registro consultable de lo que el hombre ha dicho" (Geertz 30) y lo traslada a un nuevo espacio, donde pueda llegar a formar parte del lenguaje de un "registro consultable" diferente.

El reto sería, entonces, la posibilidad de trasladar a través de distintas culturas una descripción cultural densa. Y, más allá de eso, en el caso del teatro, el reto es hacerlo dentro de un espacio recientemente constituido, que abarque a los creadores y al público, con el fin de compartir y posibilitar la traducción. No se trata de crear un equivalente o una reproducción, que en este caso no tendría sentido, sino de establecer y saber cómo reconocer el rigor potencial del texto, de confiar en su habilidad de viajar. En el contexto de la traducción del extremo cultural, el objetivo es facilitar el reconocimiento de las estructuras simbólicas de la historia que se han reubicado y provocar un asalto, una disrupción de la conciencia en el espacio doméstico. El traductor como activista cultural potencial: la traducción del extremo cultural busca seguir los senderos que conducen a momentos de conexión, así como a momentos de posible intrusión en la cultura receptora.

En la traducción de la obra de Juan Radrigán, Las brutas (1980), ${ }^{3}$ la preocupación central fue considerar el impacto que tendría en una audiencia británica la historia de un grupo de mujeres que lucharon por comprender lo que significaba el alumbrado público, los lentes para leer o la radio y la televisión. La evocación de esta marginalidad aparentemente risible no podía afectar la credibilidad del público, de manera que el lenguaje y la representación del texto debían ofrecer los mecanismos para localizar estos eventos en la larga historia de distanciamiento del avance de la modernidad. Una de las virtudes del texto consiste en la creación de un lenguaje poético que produce la fuerza dramática del argumento y lo convierte en un componente narrativo de una historia social más amplia. Basada en el caso real de tres hermanas que fueron encontradas, en los primeros años del régimen de Pinochet, colgadas de una roca junto con sus perros descuartizados, Las brutas dramatiza lo que no se sabe de esta tragedia. Nunca se supo la razón de la muerte o del suicidio colectivo de las tres hermanas. Radrigán imagina la dinámica de las tres mujeres a medida que se acercan (colectivamente o no) a la decisión de suicidarse cuando su aislamiento, su debilidad creciente y su miedo a lo que 
está sucediendo en el mundo más allá de su granja, que es algo que les resulta incomprensible, crece de manera tan inminente que solo son capaces de ver una salida: aceptar que nos son más que bestias y que ningún ser humano va a salvarlas o redimirlas. El lenguaje de la obra va más allá del recuento mismo de una historia sucedida al principio del gobierno de Pinochet, para imaginar una tragedia de embrutecimiento y de aislamiento extremos. Por un lado, se trata de un aislamiento que está vinculado ancestralmente a la vida en los Andes y que en ese periodo histórico fue exacerbado por la extrema violencia del régimen pinochetista; $y$, por el otro, es un aislamiento que está en el centro de la poética dramática de Radrigán. Durante los años de Pinochet, Radrigán volvería una y otra vez a la "misión" de representar en palabras el aislamiento deshumanizador de los sectores más marginados de la sociedad, en un lenguaje teatral que cobra vida en el momento de articulación de la toma de conciencia de la desesperación de los protagonistas y la proximidad de la pérdida de los últimos vestigios de dignidad humana.

Es aquí donde entra a jugar un papel relevante la densidad de la traducción: al excavar y convertir en presencia constante los mecanismos a través de los cuales estas historias contadas operan y comunican. A través de la traducción densa, la obra de teatro se puede convertir en un "registro consultable" de cómo un dramaturgo contó una determinada historia y de este modo puede operar en cada oportunidad con un nuevo grupo de interlocutores. El tejido escrupuloso y concienzudo de los diferentes hilos conectores permite que la obra se vuelva traducible en términos tanto de distancia como de presencia. En nuestra producción de Las brutas, Sue Dunderdale tomó la decisión de incorporar a la obra imágenes del 11 de septiembre de 1973, cuando se produjo el golpe de estado de Augusto Pinochet, y de la canción del famoso cantante chileno Víctor Jara, "Plegaria a un labrador". La idea no era ubicar la obra de manera unidimensional como un texto sobre la dictadura, sino provocar un punto inicial de contacto para permitir un modo de ingreso. Se trataba de decir: esta obra tiene un contexto, cuenta una historia verdadera, algo que en realidad sucedió, no se trata solo de un argumento sino de una forma de recordar un evento trágico cuyas raíces se pueden rastrear, aunque no se presenten todos sus detalles concretos. De esta manera, se crea un momento de exceso más allá de la obra, con el fin de sugerir un punto de reconocimiento de la historia del otro. Es en este punto que se inicia el proceso de hacer que el público tenga a su disposición los distintos vínculos. La obra en proceso de producción ofrece el material para la "liberación de un resto" que "excede la comunicación en un solo sentido" (Venuti 484). 
Se trata de un resto literario - comparaciones con la exploración realizada por Chéjov sobre las relaciones entre hermanas, el lenguaje dramático de Beckett y la poética de Synge, por ejemplo-, y también emocional, social y político, en lo que respecta al tipo de conexiones que despierta en el presente de la puesta en escena. El impacto devastador del extremo aislamiento social, económico, geográfico y afectivo traspasa los límites de la narración de una historia andina. Las referencias al golpe militar permiten mantener el relato en una sugerida realidad distante, pero la resistencia de Radrigán a proponer un comentario político permite que la obra viaje. Es por eso que el proceso de traducción debe confiar en la capacidad del lenguaje de resistir la serie de actos hermenéuticos a través de los cuales se realiza el potencial migratorio de la obra y es de este modo como hacemos posible su traducibilidad. La transformación que se realiza a través de la traducción y de la "re-petition -en el sentido de volver a interrogar" (Steiner 318$)^{4}$ - exigía que en el espacio de los ensayos se repitiera el proceso de migrar con la obra y establecer su lugar de manera coherente, aunque no pasiva, dentro del nuevo orden simbólico al que ahora la obra iba a pertenecer.

Otra obra de Radrigán, Hechos consumados (1981), presenta problemas diferentes en términos de la traducción y nos lleva al centro de los temas planteados aquí. Escrita también durante la dictadura de Pinochet, cuenta la historia de una joven a quien un mendigo rescata de un canal. Mientras esperan que las ropas se sequen, los dos personajes conversan, mirando una larga fila de gente que sale del pueblo sin tener aparentemente ningún destino ni dirección. El vigilante de la propiedad en la que se encuentran les pide que sigan su camino. El indigente, llamado Emilio, se niega a irse, enfrentándose a una autoridad irracional. Entonces el vigilante - que está protegiendo su trabajo, cuidando a su esposa moribunda y ni siquiera sabe quién es en realidad su jefe- lo golpea hasta matarlo. El reto de esta obra es que parece dar pie a una traducción no mediada. No es difícil transferir el extremo cultural de la indigencia y la destitución, como una manera de denunciar las realidades actuales del Reino Unido, y esta resonancia cultural permite una descripción densa a través de la cual podemos comenzar a examinar el contexto. La tarea consiste en resistir el deseo inmediato de entregarse a la traducción

4 En la cita original, "re-petition - an asking again", puede significar al mismo tiempo volver a pedir y volver a preguntar. En este contexto, los dos significados son válidos, pero la repregunta resulta más pertinente (Nota de la traductora). 
y, en su lugar, confiar en el lenguaje que Radrigán ha creado para intentar recrear un impacto similar a través de la poética del lenguaje de la nueva obra. Radrigán crea un lenguaje que dramatiza la emergencia en palabras de lo que queda de humanidad en la devastación producida por la pobreza y la extrema marginalidad. Este lenguaje no se puede transferir directamente a una comprensión coloquial inmediata, porque debe retener la fuerza que permite expresar la memoria del otro yo, pasado y perdido, que una vez fue humano, que formaba parte de una familia, que conoció el amor y tuvo hijos, y que de ese modo compartió un lenguaje común con los demás "en el centro de la vida y al margen", como ha dicho Radrigán. En su versión original, la intención de la obra era irrumpir en el presente, de manera lingüística y por tanto política, para interrumpir la recepción fácil, para obligar al esfuerzo de comprender y de esa manera forzar la observación de la realidad circundante. En la traducción de la obra lo que se busca es replicar este efecto. Esto nos lleva al centro de la cuestión: este tipo de traducción "pone en evidencia la posición de sujeto que ocupa el traductor", como sostiene Theo Hermans (27). Desde la posición de quien se ubica entre dos orillas y en el punto en el que se conectan diferentes mareas de memorias, el traductor va descubriendo la obra que puede forzar la atención en la cultura meta, y esto puede abrir el camino hacia un lenguaje que exprese lo que está alrededor y no podemos ver. La importancia de la traducción densa consiste en que a través de ella nos desplazamos de inmediato, más allá de la abstracción, hacia un tenaz cuestionamiento que, a su vez, se transforma en el impulso de crear vocabularios renovados para la puesta en escena.

Peter Brook nos cuenta cómo empieza a trabajar en una obra: "Comienzo con una intuición profunda y sin forma. Mi relación con la obra es esa intuición sin forma. Estoy convencido de que esta obra tiene que montarse hoy y sin esa convicción no puedo hacerlo" (Brook 3 ). Schechner sostiene que "las obras se montan por todo tipo de razones, muy rara vez porque "debe ser montada", y nos advierte que "las actitudes moralistas con respecto al texto y a los ensayos que siguen al pie de la letra las intenciones del autor - cuando estas se conocen, lo que no sucede muy a menudo- resultan producciones poco satisfactorias" (xli). Aaltonen nos recuerda que cada lector/traductor de un texto es solo uno de sus muchos "ocupantes"; y que "el investigador apenas puede informar sobre lo que es visible y leer en el texto el significado que él mismo le otorga como lector" (29). La práctica de traducción del extremo cultural que intento formalizar a través de esta aproximación, toma 
en cuenta todas estas advertencias y se sostiene en el hecho de que la "intuición" va a ser cuestionada en cada etapa del camino y no llegará a ser puesta en escena a menos que exista una convicción compartida sobre la obra que resista el cuestionamiento al que va a someterla la práctica teatral. Esta es, entonces, mi intuición sin forma: hay obras chilenas y latinoamericanas que tienen algo importante que decirnos en este momento político en el que nos encontramos en el Reino Unido. En lugar de buscar las diferencias escénicas en la traducción de obras que cuentan historias cómodamente distantes de nuestra experiencia, manteniendo así la ilusión de la diferencia, este tipo de traducción busca obras que generen un teatro de reconocimiento radical. El reconocimiento de que tal vez las interrogantes que nos hace hoy nuestra misma cultura, nuestra sociedad, pueden encontrar una forma de articularse en historias de sociedades con las cuales preferimos no compararnos, sobre todo si se trata de historias que nos recuerdan cómo vivíamos hace décadas, y que nos anuncian lo que se está preparando en la trastienda de nuestra realidad contemporánea. El espectáculo del rescate de los mineros, en su gloriosa modernidad, apela a una sensibilidad basada en el gran relato del progreso y la fortaleza humana, que valora ante todo el reconocimiento. Los detalles y la profundidad de las historias de los mineros revelan las realidades subterráneas que, como muy bien lo saben los rescatados, se mantienen en el ámbito de lo impronunciable, de lo que solo se puede conocer de manera parcial, pero que revela sin embargo una parte de la vida del minero. La "profunda intuición sin forma" es, de hecho, mucho más que eso: es una percepción densa de las formas culturales en las que se encarnan los relatos de los otros, que sugiere puntos de contacto menos prometedores.

La convicción de que una obra "debe ser montada hoy" es de hecho un acto político en sí mismo. Puede resultarnos sorprendente, y puede ser incluso motivo de vergüenza para nosotros, descrubrir que las obras teatrales del Chile de los años 1960, 70 y 80 - un periodo de rápido cambio revolucionario, seguido de una dictadura que llevó a cabo una violenta represión- dialoga con nuestra realidad aquí y ahora. Pero así es. Egon Wolff (1926) dramatizó el miedo de los sectores medios y altos, destacando la precariedad de la posición en la que se encontraban en la sociedad y el miedo a la invasión violenta de sus espacios de poder y seguridad económica por parte de las clases bajas y los desposeídos. Isidora Aguirre (1919-2011) volvió una y otra vez al problema del olvido colectivo de las luchas sociales, a las batallas libradas tantas veces para que se reconocieran los derechos humanos y a la importancia de la memoria articulada en la voz femenina. Y Juan Radrigán, 
como hemos visto, le rinde homenaje a la dignidad humana y a la equivocación, en su insurgencia dramática dentro de la vida y el lenguaje de los más desposeídos en la sociedad. Y estos son solo algunos casos. Las estructuras de poder desde las cuales emerge el impulso del autoritarismo es una de las líneas que recorre también el trabajo de Marco Antonio de la Parra (1952), Ramón Griffero (1952) y Benjamín Galemiri (1958), y adquiere una evidente significación en el contexto de una sociedad como la británica que ha creído de manera complaciente en sus narrativas dominantes sobre la democracia sin fisuras y sobre las virtudes de su régimen parlamentario.

La traducción que, en ese contexto, intenta moverse entre estos extremos, adopta "un proceso doméstico totalizante" (Venuti 483) que funciona como una crítica potencialmente radical de la sociedad receptora, no de la sociedad de origen. No estaríamos comentando lo ajeno, sino lo nuestro. Pero el asunto es: ¿cómo le damos fuerza a esa "misión”, cómo la hacemos funcionar? En este punto entra en juego lo que Peter Brook llama "la cultura de los vínculos":

Es la fuerza que puede contrarrestar la fragmentación del mundo en que vivimos. Tiene que ver con el descubrimiento de relaciones, cuando esas relaciones se han perdido o han quedado latentes - relaciones entre el hombre y la sociedad, entre una raza y otra, entre el microcosmos y el macrocosmos, entre los humanos y las máquinas, entre lo visible y lo invisible, entre categorías, lenguajes y géneros. ¿En qué consisten esas relaciones? Sólo los actos culturales pueden explorar y revelar esas verdades. (239)

Esta necesidad de un acto cultural que explore y revele está basada, en palabras de Benjamin, en "algo inalienable para nosotros, la más segura de nuestras posesiones [...] la habilidad de intercambiar experiencias" (83). El tema que me preocupa aquí es la forma de ese intercambio, cuando una persona o un grupo toma decisiones sobre la necesidad de traducir e invita a otro grupo a involucrarse en la experiencia. El proyecto "Traducir el extremo cultural" está basado en un sentido del espacio que ocupamos dentro de la comunidad, un sentimiento físico de la localización y del desplazamiento a través de lo literario, de los idiomas y también de la experiencia, las diversas formas de expresión y lo que se escapa de las narrativas políticas dominantes y de los relatos que circulan por los medios. Este tipo de traducción está relacionada con archivos e intercambios, con el acopio de datos y con el uso de las habilidades y los saberes de distintas áreas para comprender las estructuras profundas que permiten la construcción de significados. No se 
trata de una cuestión teórica, sino de una práctica, aunque toda práctica válida genera sus propias teorías, sus maneras de pensarse a sí misma. Cuando traducimos para el teatro aprendemos a comprender los modos en que el autor ha estructurado sus materiales para construir un relato coherente. No intentamos crear una réplica estática de los gestos y los actos, sino aprehender el momento de la creación, descifrarlo, interpretarlo - fijarlo tanto como sea posible, aunque sea por un momento-, con el fin de localizarlo y de poder ingresar de manera radical a la información necesaria para la puesta en escena que el texto contiene. Esta forma de domesticación radical busca un complejo traslado hacia el terreno de lo familiar, a través del cual el eco de la voz del otro articule la posibilidad de una cultura de vínculos.

Al explorar la traducción de lo que percibimos como un extremo cultural, estoy buscando una manera particular de interrogar esas formas narrativas y su modo de narrar en otras culturas que parecen sugerir un vínculo localizable en la sociedad británica en la que vivo aquí y ahora. No hay nada pasivo en este tipo de aproximación. No se les pide a las obras que ofrezcan un sentido con el fin de que comprendamos el texto y el contexto, sino que hablen más allá de sí mismas, que disparen "las flechas del sentido" tanto de ida como de vuelta (Steiner 318). La comprensión del lugar desde el cual han sido escritas se convierte en el acto de imaginar hacia qué lugar podrían proyectarse, dónde más podrían instalarse. Se trata de la tarea de la hermenéutica que, en palabras de Ricoeur, consiste en "reconstruir la dinámica interna del texto y restaurar a la obra su habilidad de proyectarse fuera de sí misma en la representación de un mundo que yo también podría habitar" (18). Y aquí está el otro aspecto de la subjetividad que es necesario considerar: la convicción y el reconocimiento de que las historias que se cuentan en un lugar surgen de lo que es necesario decir, y puede ser repetido en otra parte y en momentos distintos.

Para que esto suceda, para que se pueda realizar de manera completa, tiene que existir en muchas personas la convicción de que será posible. El "éxito" - en todos sus complejos significados- solo se da cuando una cantidad suficiente de gente se compromete en el proceso de transportar lo que ha sido descubierto originalmente por una sola persona y en reconocer y expresar lo que es necesario decir. Si el momento de reconocimiento parece instintivo, entonces el proceso demanda exactitud interpretativa: la traducción no nos ofrece significados sino que nos dice cómo alcanzarlos. De manera que es fundamental el ingreso a una densidad cultural e histórica. El objetivo es descubrir desde dónde se escribe la obra, no para "encontrar las 
palabras correctas" ni para lograr alguna forma de fidelidad perdida, porque ese es un objetivo que nos conducirá siempre a la esterilidad. La idea es conocer el origen y la resonancia que la obra produce. Cómo se ubica en el aire que la rodea. Cómo puede ser contada, recibida, comprendida y ordenada de nuevo. Porque la nueva obra tiene que sobrevivir en un aire distinto y, aunque la pregunta por lo que significaba o por las respuestas que originalmente produjo puede rondar durante el proceso que conduce a la puesta en escena (de una manera genuinamente interesante y productiva), la nueva pregunta debe referirse a la habilidad de comprometernos profundamente en distintas formas de interacción, reconocimiento, provocación y renovación.

"El traductor", según Steiner, quien utiliza una metáfora minera muy apropiada en este caso, "invade, extrae y se lleva algo a casa" (314). A veces lo que nos traemos a casa es el lenguaje de lo que se vive en la realidad que nos rodea y lo que no hemos podido percibir o no podemos reconocer en la voz que nos habla desde la distancia. Descifrar este enigma en el contexto de nuestra propia realidad -y a veces reconocerlo como nuestra propia realidad- en una sociedad que muy rápidamente se está poniendo a la par de los países del "tercer mundo" es el trabajo del que trae a casa el extremo cultural. La realidad externa de este nuevo contexto al que fue traída la obra tuvo un impacto directo en nuestra producción de una manera que no hubiéramos podido preveer, a pesar de la convicción de que Las brutas nos pertenecía aquí y ahora. Cuando comenzamos los ensayos, estallaron en Londres tres días de disturbios que afectaron a toda la ciudad en agosto de 2011. La diseñadora Lorna Ritchie se dedicó a buscar entre los escombros, como hacen todos los diseñadores que trabajan en obras alternativas, y encontró maderas y otros desperdicios en las zonas donde hubo disturbios. Estos materiales se utilizaron para armar el escenario y para recrear una historia que habla de los seres más olvidados de todos.

\section{Obras citadas}

Aaltonen, Sirkku. Time-Sharing on Stage: Drama Translation in

Theatre and Society. Clevedon: Multilingual, 2000. Impreso.

Appiah, Kwame Anthony. "Thick Translation". The Translation Studies Reader.

Ed. Lawrence Venuti. London: Routledge, 2000. 417-429. Impreso.

Benjamin, Walter. Iluminations. 1955. Trans. Harry

Zorn. London: Pimilco, 1999. Impreso.

Brook, Peter. The Shifting Point. 1987. New York: Theater

Communications Group, 1994. Impreso. 
Geertz, Clifford. The Interpretation of Cultures. 1973.

New York: Basic Books, 2008. Impreso.

Hermans, Theo. The Conference of the Tongues. 2007.

London: Routledge, 2014. Impreso.

Ricoeur, Paul. From Text to Action: Essays in Hermeneutics.

1991. Evanston: Northwestern UP, 2006. Impreso.

Salazar, Gabriel. La historia desde abajo y desde dentro.

Santiago: U. de Chile, 2003. Impreso.

Schechner, Richard. Environmental Theater. New York: Applause, 1994. Impreso.

Steiner, George. After Babel: Aspects of Language and

Translation. 1975. Oxford: Oxford UP, 1998. Impreso.

Venuti, Lawrence. "Translation Community Utopia". The Translation Studies

Reader. Ed. Lawrence Venuti. London: Routledge, 2000. 468-488. Impreso. 